385

UNPLANNED, UNEXPECTED AND UNATTENDED DELIVERY (UUUD)

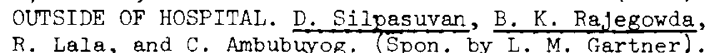
Misericordia. Lala, and C. Ambubuyog. (Spon. by L. M. Gartner

tion, Department of Pediatrics, Bronx, N. Y.

In the USA, very little data is available on UUUD. Maternal characteristics and perinatal outcome of 70 UUUD from oct.' 76 to Nov. ' 77 were identified. All mothers of UUUD were admitted to Lincoln Hospital within $4 \mathrm{hrs}$. of delivery. During the same period, there were a total of 3,703 in-hospital deliveries (HD), giving an UUND incidence of 18.5 per 1,000 $\mathrm{HD}$. The main features of UUUD consist of: 1) $59 \%$ Black (23\% HD); 2) $37 \%$ more than 24 yrs. old $(28 \% \mathrm{HD})$; 3) $17 \%$ with parity more than $3(12 \% \mathrm{HD}) ; 4) 77 \%$ on public assistance ( $43 \% \mathrm{HD})$; 5$) 89 \%$, education below high school $(76 \% \mathrm{HD}) ; 6) 58 \%$ no prenatal care $(19 \% \mathrm{HD})$; 7$) 67 \%$ broken families $57 \% \mathrm{HD})$; and 8$) 13 \%$ drug-addicted ( $4 \% \mathrm{HD}$ ). Low-birth-weight rate (no. $\leqslant 2,500 \mathrm{gm} / 1,000$ livebirth), perinatal mortality rate (no. per 1,000 deliveries) and neonatal mortality rate (no./1,000 livebirtt) associated with UUUD are compared with those of HD as below:

\section{Total Number}

Low-birth-weight Rate

Perinatal Mortality Rate

Neonatal Mortality Rate

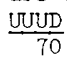

303

$\frac{\mathrm{HD}}{703}$
115

115
30

10

D. Value

$<0.001$

$<0.001$

$<0.005$

The UUTD is associated with poor antenatal planning, lack of education and low socfoeconomic condition. These mothers are at great risk for future pregnancies and must be provided with

intensive education and medical care.

\section{EVALUATION OF TOTAL RADIATION EXPOSURE IN NEWBORI}

386 INTENSIVE CARE. Wilbur Smith, E. Gresham, R. Berg, L. L. Baehner). Indiana Univ. Sch. of Med., Ind1ana University Hospitals, Departments of Radlology and Pediatrics, Indlanapolis. Total radiation exposure of newborns in intensive care has no been directly evaluated previously. Reusable calcium and 11thium fluoride crystals with a sensitivity of one mem and an accuracy of $\pm 10 \%$ were used for direct measurement of the radiation exposure of 133 consecutive infants. Two calibrated crystals were placed in the $x$-ray fleld during all radiographic procedures. Technical data including number and type of radiographs were recorded and subsequently correlated with exposure measurements. The average technique was 60 and $65 \mathrm{KVP}$ at 1 MAS for chest and abdominal films, respectively. Chest radiographs gave an average skin exposure of $7.3 \mathrm{mRem}$ (range $2.0-15 \mathrm{mRem}$ ); the maximum abdominal exposure was 16 mRem per examination. During these patients intensive care stay, $14 \%$ received a total skin exposure of $>100$ intensive care stay, $14 \%$ received a total skin exposure of $>100$
mem. The highest recorded was 286 mRem in a chfld who underwent mRem. The highest recorded was 286 mRem in a child who underwent tient permitted a calculation of potential gonadal exposure due to abdominal radiographs. The average per f1lm was $4.4 \mathrm{mRem}$ for male and 2.2 mRem for female infants. If gonad shields had not been used, $29 \%$ of the babies would have recetved $>15 \mathrm{mRem}$ and $56 \%$ 10 mRem total gonadal exposure. Infants adjacent to babies being radiographed recelved negligible scatter radiation. This study describes a novel technique for newborns which permits sensitive monitoring of accumulative radlation exposure and may be useful in establishing radiation limits for infants.

\section{7}

BLOOD PRESSURE DURING PREGNANCY AS A PREDICTOR OF SUBSEQUENT BLOOD PRESSURE IN THE CHILD.

Jay M. Sosenko, R. Curtis Ellison, Olli S. Miettinen (Spon. by Alexander S. Nadas). Harvard Medical School, Children' Hospital Medical Center, Department of Cardiology, Boston, Mass.

The value of maternal blood pressure during pregnancy (MBP) as a predictor of the child's blood pressure (CBP) at 7 years was explored in a prospective, follow-up study of 5,926 pregnancies. the 16 th and 32 nd weeks of pregnancy (mean number of readings $=3$ ). The table below shows selected percentiles of CBP for categories The table below shows selected percentiles of CBP
of the mother's systolic blood pressure (MSBP).

\begin{tabular}{|c|c|c|c|c|c|c|}
\hline MSBP & & $95-104$ & $105-114$ & $115-124$ & $125-134$ & $135-144$ \\
\hline \multirow{3}{*}{$\begin{array}{l}\% \text { ile } \\
\text { of CBP }\end{array}$} & 10 th & $89 / 47$ & $90 / 49$ & $90 / 48$ & $90 / 48$ & $92 / 49$ \\
\hline & 50 th & $103 / 62$ & $103 / 63$ & $103 / 63$ & $104 / 63$ & $106 / 65$ \\
\hline & 90 th & $116 / 74$ & $118 / 74$ & $117 / 74$ & $118 / 74$ & $121 / 78$ \\
\hline
\end{tabular}

CBP shows almost no trend over the MSBP categories up to 135 mHg. The increment at this level is statistically significant $(p=.001)$ by one-sided $t$ test for both systolic and diastolic ressures in the child.

We suggest that the overall predictive value of MSBP during regnancy for subsequent blood pressure in the child is poor. imilar results were obtained for diastolic blood pressure in th nother.

388

EPIDEMTOLOGY OF OTITIS MEDIA DURING FIRST TWO YEARS OF LIFE. David W. Teele, Jerome 0. Klein, and Boston University School of Medicine; Boston City Hospital, Department of Pediatrics. Boston.

To determine the epidemiology of otitis media (aM) during the first two years of life we followed prospectively from birth 2565 children. At every visit we recorded results of pneumatic otoscopy and epidemiologic data. The incidence of OM by age was:

Age (months)

$0-6$

$7-12$
$13-18$

$13-18$
$19-24$

\begin{tabular}{|c|c|c|c|}
\hline \multicolumn{4}{|c|}{ cent of those in age group) } \\
\hline$\frac{0}{85 \%}$ & $\frac{1}{140}$ & $\frac{2}{1 \%}$ & \\
\hline $48 \%$ & $32 \%$ & $13 \%$ & \\
\hline $37 \%$ & $27 \%$ & $16 \%$ & 2 \\
\hline $3 \%$ & $21 \%$ & $21 \%$ & 34 \\
\hline
\end{tabular}

female). female). Having a sibling with allergy disposed propositi to

Features associated significantly with recurrent $a_{M}(\geq 3$ episodes) were those noted above. A parent with recurrent OM disposed propositi to recurrent $O M$. Breast feeding did not offer protection against recurrences of OM.

The sole feature associated significantly with persistent effusion in the middle ear after lst episode of $\mathrm{OM}$ was the practice of giving a child a bottle in bed.

\section{9}

PERSISTENCE OF AMPICILLIN-RESISTANT HAEMOPHILUS PERSISTENCE OF AMPICILLIN-RESISTANT HAEMOPHILUS INFLUENZAE TYPE B IN THE NASOPHARYNX AFTER ERADICA-
TION OF AMPICILLIN-SENSITIVE HAEMOPHILUS INFLUENZAE TYPE B BY TRIMETHOPRIM-SULFAMETHOXAZOLE. Ram Yogev, Herman B. Lander, and A Todd Davis. (Spon. by Henry L. Nadler). Northwestern Univ. Med. Sch., Children's Memorial Hospital, Department of Pediatrics, Chicago.

During an outbreak of ampicillin-resistant $H$. influenzae type $B$ (AR-HITB) in a children's chronic care facility, the carriage rates of AR-HITB and ampicillin-sensitive $H$. influenzae type $B$ (AS-HITB) were studied. Multiple culture surveys were done with 27 to 32 children cultured. As many as $81 \%$ carried AS-HITB and as many as $48 \%$ carried AR-HITB. Using special media (chocolate agar with $2 \mathrm{mcg} / \mathrm{ml}$ of ampicillin), we found that $30 \%$ of the patients carried both strains. Eradication of both strains was at tempted by administering trimethoprim-sulfamethoxazole (TMP-SMX) ( $8 \mathrm{mg} / 40 \mathrm{mg}$ ) for five days to all individuals on the ward. At the end of therapy, AS-HITB carriage had been reduced by $80 \%$ AR-HITB were not eradicated from any carrier. Doubling the dose and duration of therapy with TMP-SMX similarly had no effect on AR-HITB carriage. Agar dilution susceptibility studi revealed trailing end points for the majority of AR-HITB isolates. Nearly all AS-HITB isolates had sharp end points. These data suggest that: 1.) TMP-SMX appears to be effective in eradicating nasopharyngeal carriage of AS-HITB; 2.) This drug combination is not effective for AR-HITB carriage; and 3.) Trailing end points on in vitro agar dilution tests may provide evidence for in vivo resistance of AR-HITB to TMP-SMX.

\section{GASTROENTEROLOGY AND NUTRITION}

390

EFFECT OF GLUCOSE AND OSMOLALITY ON GASTRIC EMPTYING

IN NEWBORNS. Dean L. Antonson, Charles L. Paxson, Jr.
Jon A. Vanderhoof. Department of Pediatrics, University of Nebraska, Omaha (Spon. by Glenn C. Rosenquist) Osmolality of oral glucose-electrolyte solutions may be reduced without altering caloric content if glucose oligosaccharides (GOS) are substituted for glucose. To evaluate the effect of glucose vs GOS on gastric emptying in newborns, GOS were substituted for glucose in a 400 mosm glucose solution to reduce osmolality to 200 or 300 mosm. To assess the effect of osmolality alone on gastric emptying, a 200 mosm glucose solution was increased to 300 or 400 mosm by adding the nonmetabolized pentose xylose. Effect of glucose concentration alone was assessed by comparing 200 vs 400 mosm glucose solutions. On the second day of life, six groups of 5 healthy term newborns were fasted 3 hours. Sixty cc of the test solution containing $5 \mathrm{~g} / 1$ polyethylene glycol 5000 (PEG) as a marker was instilled into the stomach. After 28 minutes, $3 \mathrm{mg}$ of phenol red was instilled and allowed to equilibrate for 2 minutes. Contents were then aspirated and assayed for PEG and phenol red. The following milliliters of original solution remained in the stomach: \pm SEM

original solution remained in the stomach: \pm SEM
OSM glucose/GOS glucose/xylose glucose alone $\left.\left.\left.\begin{array}{llrl}\text { OSM } & \text { glucose/GOS } & \text { glucose/xylose } & \text { glucose alone } \\ 200 & 34.8 \pm 4.1 \\ 300 & 43.1 \pm 4.1 \\ 400 & 41.0 \pm 5.0\end{array}\right\rangle p>.2 \begin{array}{r}35.8 \pm 5.0 \\ 39.5 \pm 4.1 \\ 31.3 \pm 2.2\end{array}\right\rangle p>.2 \quad \begin{array}{c}35.8 \pm 5.0 \\ 41.0+5.0\end{array}\right\rangle p>.2$ 400 We conclude that osmolality does not effect gastric emptying in we conclude $200-400$ mosm in newborns and substitution of glucos by GoS will not enhance gastric emptying of infant formulas or 